\title{
COMPARATIVE STUDY OF THE CLINICAL RESPONSE OF PATIENTS TO DIFFERENT TREATMENT REGIMENS IN RHEUMATOID ARTHRITIS
}

\author{
DIANA IOANA MANUELA TEAHA ${ }^{1 *}$, NICOLETA-ANAMARIA PAȘCALĂU $^{2}$, LIVIU LAZĂR $^{1}$ \\ ${ }^{I}$ Doctoral Studies Department, Biomedical Science, 1 University Street, Oradea, Romania \\ ${ }^{2}$ Faculty of Medicine and Pharmacy, Department of Medicine-Psycho-Neuroscience and Recovery, $101^{\text {st }}$ Decembrie Street, \\ Oradea, Romania
}

*corresponding author:dteaha@yahoo.com

Manuscript received: July 2018

\begin{abstract}
There are different therapeutic solutions available for rheumatoid arthritis (RA) patients, suitable for different stages and different comorbidities. The outcome depends on both the patient's clinical response and the therapeutic treatment chosen. The main clinical objectives are slowing the progression of disease and the effective management of patient symptoms, avoiding as far as possible the irreversible damage on the joints and cartilages. In this study we observed four different treatment strategies available and recommended in RA in terms of therapy response considering the stage of RA that the patients were in, as well. The strategies involved, included methotrexate in monotherapy, methotrexate combined with biological therapy, methotrexate and corticotherapy and methotrexate and physiokinetotherapy. Following this study, the most efficient statistically in the treatment response, were the patients included in the group of methotrexate combined with biological therapy.
\end{abstract}

\section{Rezumat}

Există soluții terapeutice diferite pentru pacienții cu artrită reumatoidă (PAR), potrivite pentru diferite etape și diferite comorbidități asociate pacienților. Rezultatul depinde atât de răspunsul clinic al pacientului, cât și de terapia aleasă. Obiectivul clinic principal este încetinirea progresiei bolii și gestionarea eficientă a simptomelor pacientului, evitând, pe cât posibil, deteriorarea ireversibilă asupra articulațiilor și cartilajelor. În studiul de față am urmărit patru strategii diferite de tratament disponibile și recomandate în PAR, în ceea ce privește răspunsul terapeutic, luând în considerare și stadiul de încadrare al pacienților în afecțiune. Strategiile terapeutice au inclus metotrexatul în monoterapie, metotrexatul combinat cu terapia biologică, metotrexatul și corticoterapia și metotrexatul şi fiziokinetoterapia. În urma acestui studiu, cele mai sugestive date statistice în răspunsul la tratament, au fost regăsite la pacienții incluși în lotul tratat cu metotrexat combinat cu terapia biologică.

Keywords: rheumatoid arthritis, clinical response, methotrexate, corticotherapy, physiokinetotherapy

\section{Introduction}

Rheumatoid arthritis (RA) is a progressive chronic arthropathy that affects about $1 \%$ of the general population [18]. It causes deformations and destroys joint and cartilages, evolving on a systemic level in many cases $[8,9]$. From an etiological point of view, the causes of developing RA are still unclear [13]. It is defined as an autoimmune disease that affects the conjunctive tissue [21], it produces bilateral erosive synovitis, and is characterized by the presence of several antibodies [14].

The inflammatory mechanism in RA is explained by the activation of pro-inflammatory cytokines (IL-6, $\mathrm{TNF} \alpha$, etc.) along with a wave of cells involved in the immune and inflammatory response [15]. This mechanism underpins the development of existing biological treatment, highly selective therapy, with molecular alignment [6].
The most common in the RA biological therapy in Romania are: anti-TNF $\alpha$ agents (adalimumab, etanercept, infliximab, certolizumab), anti-T cell (abatacept), antiB cell agents (rituximab) $[4,16]$.

The actual protocols in rheumatology in terms of RA management are recommending a step by step kind of strategy [16]. The patients are usually initiated with a DMRD's, like methotrexate (first intention), sulfasalazine, leflunomide or hidroxychloroquine if there is an intolerance to methotrexate. It can also be associated with NSAID's, corticotherapy, physiotherapy, or combination of DMRD's, depending on the patient's response and the stage of the pathology [11]. The decision of the biological therapy is taken if the patient doesn't respond to the basic treatment at the correct doses, and for an optimal duration, respectively, if the patient received at least 2 standard remission therapeutics, at least 12 weeks each, one being 
represented by methotrexate, unless it is proven to be contraindicated [19].

The therapeutic response is different depending on many factors, including the individuality of the patient, the disease stage, the activity of the disease. The best outcome, based on the scientific data collected so far, come from early diagnosis and treatment, in order to avoid progression and irreversible damage on joints [12]. In the RA monitoring, it is essential for the criteria to be reproducible, validated, modifiable and non-prescriptive [5].

\section{Materials and Methods}

The principal aim of the study was to evaluate the patient's clinical response in different disease stages with various treatment strategies in rheumatoid arthritis [2] in order to establish the best statistical therapeutic outcome.

Between 2015 and 2017, we selected 85 patients who were monitored during one year of therapy for the disease with 3 clinical assessments: initially, after 6 months and after 12 months of treatment.

We tracked patients' progression according to the disease stage, as follows: stage I (39 patients), stage II (34 patients), stage III + IV, advanced (12 patients). We followed the clinical response of patients divided in 4 different groups, according to different treatment strategies, as follows: Group 1: methotrexate (MTX) monotherapy (34 patients); Group 2: MTx + biological therapy (14 patients); Group 3: MTx + corticotherapy (17 patients); Group 4: MTX + physiokinetotherapy (20 patients).

The patients in the $1^{\text {st }}$ group received methotrexate monotherapy, between 10 - $20 \mathrm{mg}$ weekly, depending on patient's tolerance for the molecule.

In the $2^{\text {nd }}$ group, we enrolled patients in treatment with biological therapy, either with a starting dose of $200-300 \mathrm{mg}$ infliximab every 2 weeks for one month and a half, followed by $200-300 \mathrm{mg}$ every 8 weeks as the maintenance dose, $40 \mathrm{mg}$ every 2 weeks of adalimumab or $50 \mathrm{mg}$ etanercept weekly in combination with 10 - $20 \mathrm{mg}$ methotrexate weekly. Dosage for each patient was based on the individual's needs.

The $3^{\text {rd }}$ group enrolled patients treated with $10-20 \mathrm{mg}$ of methotrexate weekly in combination with corticotherapy, either q.d. 5 - $20 \mathrm{mg}$ prednisone, q.d. $5 \mathrm{mg}$ dexamethasone, q.d. 16 - $32 \mathrm{mg}$ methylprednisolone. In the $4^{\text {th }}$ group, patients enrolled were in treatment with 10 - $20 \mathrm{mg}$ methotrexate weekly and additional physiokinetotherapy: hot/cold application, electrical stimulation or hydrotherapy.

The clinical response was evaluated based on: serologic variation in inflammatory markers such as $\mathrm{C}$ reactive protein (CRP), erythrocyte sedimentation rate (ESR), rheumatoid factor (RF), and Anti-citrullinated protein antibodies (ACPAs) [20]; Disease Activity Score (DAS 28), Simple Disease Activity Index (SDAI), VAS scale (score) [10].

Statistical analysis

The statistical analysis was performed using SPSS 19. All the average parameter values, standard deviations, frequency ranges, and statistical significance tests were calculated using the Student method - $t$ test and $\chi^{2}$. ES was used to measure the sensitivity to change ( $\mathrm{ES}<0.2$, without modification; $\mathrm{ES}=0.2-0.5$, small modification, $\mathrm{ES}=0.5$ - 0.8. moderate modification, ES $>0.8$, significant modification). $\mathrm{p}<$ 0.05 value was attributed to statistical significance.

\section{Results and Discussion}

The groups where mainly formed by females $(79.49 \%$ in stage I, $88.24 \%$ in stage II and $91.67 \%$ in stage III + IV), versus males individuals (20.51\% stage I, $11,76 \%$ in stage II, respectively $8.33 \%$ in stage III + IV) with an average age between 56.51 (stage I) and 61.71(stage II), 58.42 (stage III + IV).

As expected from a progressive disease like RA, the longest duration of the disease was found in the most advanced stages (III + IV), patients with an average of 5.92 years of disease, followed in order by stage II patients (2.44 years) and stage I patients (1.03).

As a history of medication taken, most patients have had a previous treatment with methotrexate $(12.82 \%$ stage I, $44.12 \%$ stage II, $58.33 \%$ stage III + IV), patients taking biological therapy where found from stage II $(5.88 \%)$ upwards to stage III + IV (25\%), but the most common drug class found in the majority of patients were NSAIDs $97.44 \%$ (stage I), with a gradual decreasing path as the evolution of stages $91.18 \%$ (stage II) and $83.33 \%$ (stage III + IV). Corticotherapy was also found in previous treatments: $28.21 \%$ (stage I), $38.24 \%$ (stage II) and $41.67 \%$ (stage III + IV) (Table I).

For the 4 different treatment strategies, the patients were distributed based on their stage of disease as follows: in stages I and II, the applied therapy was mainly MTx monotherapy (43.59\%, respectively $44.12 \%)$, followed by MTx + physiokinetotherapy $(28.21 \%$, respectively $23.53 \%)$. In the more advanced stages (III, IV) the applied therapy was mainly MTx + biological therapy $(50.0 \%)$, followed by MTx + corticotherapy $(25.0 \%)$ (Figure 1).

We evaluated the serologic evolution throughout the whole study period, so we can acknowledge a more accurate view of the therapeutic response in the 4 different treatment strategies (Figure 2). 
Table I

Groups characteristics

\begin{tabular}{|c|c|c|c|}
\hline & Stage I & Stage II & Stage III + IV \\
\hline Sex (women/men) & $79.49 \% / 20.51 \%$ & $88.24 \% / 11.76 \%$ & $91.67 \% / 8.33 \%$ \\
\hline Average age (years) & $56.51 \pm 7.21$ & $61.71 \pm 8.37$ & $58.42 \pm 12.01$ \\
\hline Average duration of the disease (years) & $1.03 \pm 0.49$ & $2.44 \pm 1.28$ & $5.92 \pm 2.73$ \\
\hline Previous treatment & & & \\
\hline MTx & $12.82 \%$ & $44.12 \%$ & $58.33 \%$ \\
\hline Biological therapy & $0.00 \%$ & $5.88 \%$ & $25.00 \%$ \\
\hline Corticotherapy & $28.21 \%$ & $38.24 \%$ & $41.67 \%$ \\
\hline NSAID'S & $97.44 \%$ & $91.18 \%$ & $83.33 \%$ \\
\hline
\end{tabular}

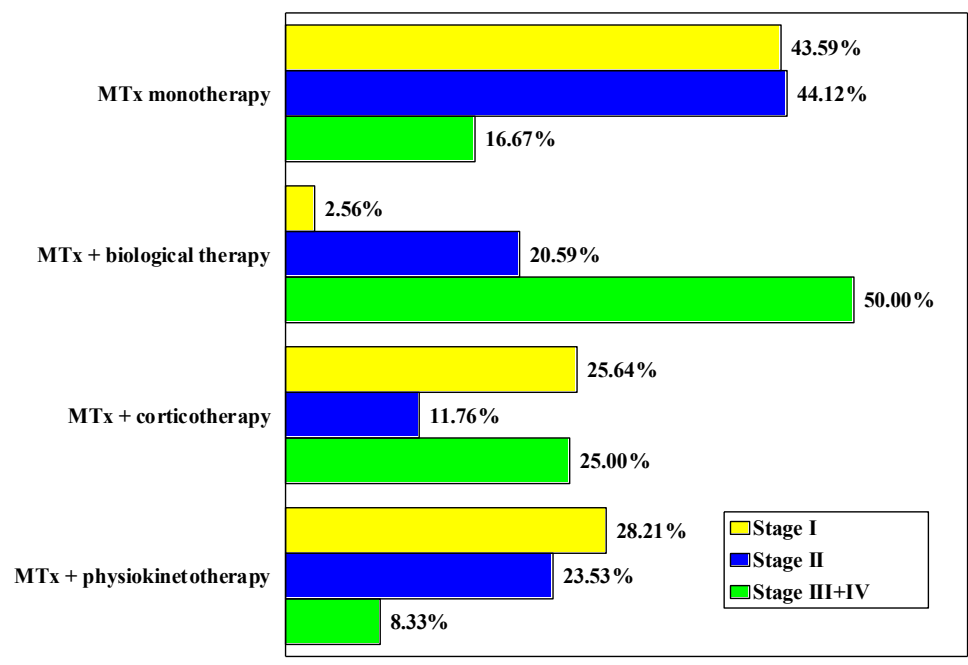

Figure 1.

Type of treatment administered at baseline

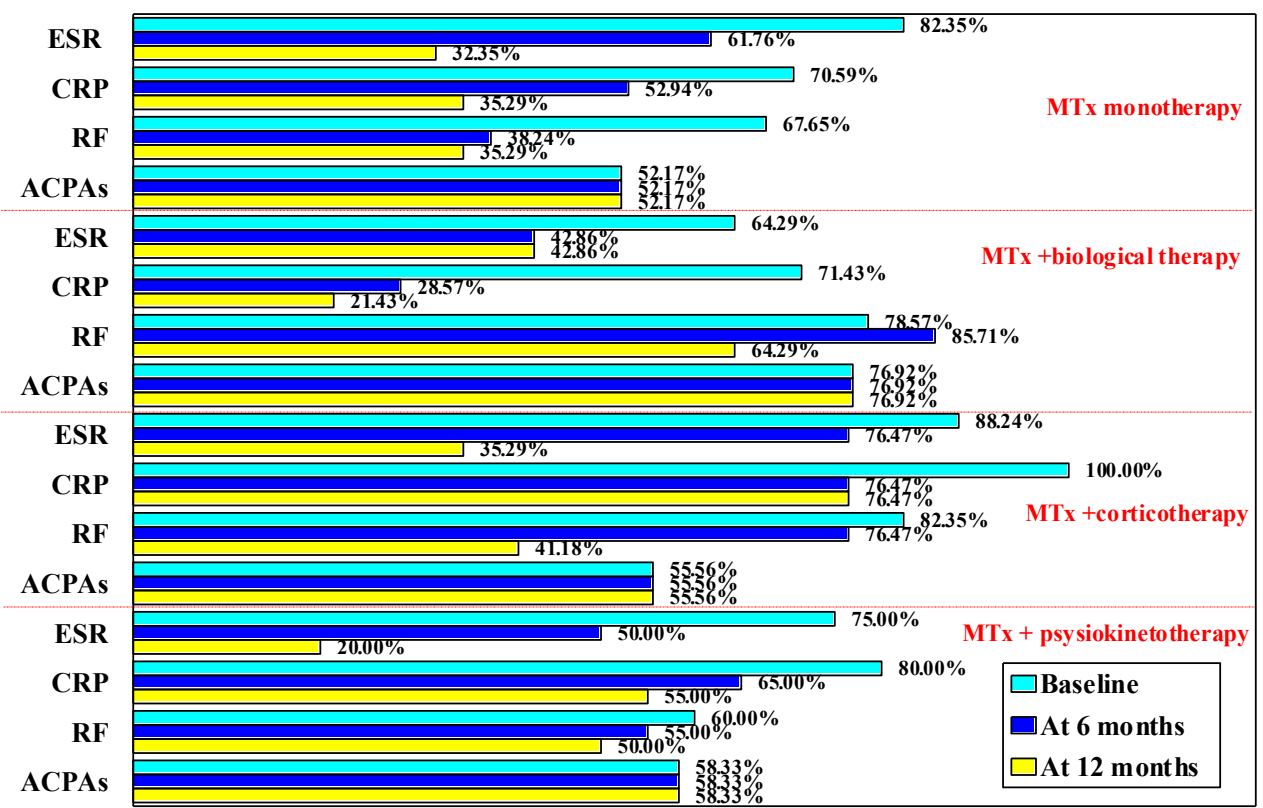

Elevated values

Figure 2.

The evolution of the serologic tests with different treatment strategies

In the MTx monotherapy group, the prevalence of the elevated ESR values were at baseline $82.35 \%$, and significantly decreasing at 12 months $(32.35 \%$, $\mathrm{p}<0.001)$. CRP values were at baseline $70.59 \%$, significantly decreasing at 12 months $(35.29 \%, \mathrm{p}=$ $0.004)$. RF values were at baseline $67.65 \%$, the progression significantly decreasing at 6 months 
FARMACIA, 2019, Vol. 67, 3

$(38.24 \%, \mathrm{p}=0.016)$ and at 12 months $(35.29 \%, \mathrm{p}=$ $0.008)$.

In the next stage, we evaluated the MTx + biological therapy group, from the serological inflammatory markers point of view. ESR at baseline was $64.29 \%$, insignificantly decreasing at 6 months $(42.86 \%, \mathrm{p}=$ 0.111 ) and maintaining throughout the 12 months study. The RF at baseline $78.71 \%$, increasing at 6 months $(85.71 \%, p=0.489)$ and decreasing slightly at 12 months, respectively $(64.29 \%, \mathrm{p}=0.241)$. CRP values were at baseline $71.43 \%$, the progression significantly decreasing at 6 months $(28.57 \%, \mathrm{p}=$ $0.002)$, at 12 months respectively $(21.43 \%, \mathrm{p}<0.001)$. In the MTx + corticotherapy group, the prevalence of the elevated ESR values were at baseline $88.24 \%$, the progression slightly decreasing at 6 months $(76.47 \%$, $\mathrm{p}=0.206)$ and significantly decreasing at 12 months $(35.29 \%, \mathrm{p}<0.001)$. CRP values were at baseline $100.00 \%$, the progression significantly decreasing at 6 months $(76.47 \%, \mathrm{p}=0.003)$ and remaining at same value at 12 months $(76.47 \%)$. RF values were at baseline $82.35 \%$, significantly decreasing at 12 months $(41.18 \%, \mathrm{p}=0.001)$.

In the MTx + physiokinetotherapy group, the ESR values were at baseline $75.00 \%$, significantly decreasing at 12 months $(20.00 \%, \mathrm{p}<0.001)$. CRP values were at baseline $80.00 \%$, significantly decreasing at 12 months $(55.00 \%, \mathrm{p}<0.001)$. RF values were at baseline $60.0 \%$, the progression insignificantly decreasing at 6 months $(55.00 \%, \mathrm{p}=0.752)$ and 12 months $(50.00 \%$, $\mathrm{p}=0.530)$.

In all types of treatment, ACPAs values remained unchanged in all three evaluations $(52.17 \%$ in MTX monotherapy, $76.92 \%$ in MTx + biological therapy, $55.56 \%$ in MTx + corticotherapy and $58.33 \%$ in $\mathrm{MTx}+$ physiokinetotherapy).

DAS28 score

The most sensitive and most used score in the present, a standard for assessing disease activity in RA, DAS28 score counts the most important 28 swollen and painful joints: shoulder, elbow, punch, metacarpophalangeal, proximal and distal interphalangeal, knee along with serologic inflammatory tests and VAS scale [21]. It is used to evaluate disease activity and guidance in therapeutic response. The overall evolution of DAS28 score in 12 months of 4 different therapeutic strategies groups can be observed.

The overall effect in 6-month evaluation on DAS28 score was moderate in MTx monotherapy, MTx + corticotherapy and MTx + physio-kinetotherapy $(\mathrm{ES}=0.63, \mathrm{ES}=0.75$, respectively $\mathrm{ES}=0.64)$, and significant in MTx + biological therapy (ES $=1.09)$, with the most cases of remission -7 patients $(50.00 \%)$. The effect registered on DAS28 score in 12-month was significant in all treatment strategies $(\mathrm{ES}=1.00$ in MTx monotherapy, $\mathrm{ES}=1.29$ in MTx + biological therapy, $\mathrm{ES}=1.13 \mathrm{MTx}+$ corticotherapy, respectively $\mathrm{ES}=1.01$ in $\mathrm{MTx}+$ physiokinetotherapy) (Figure 3).

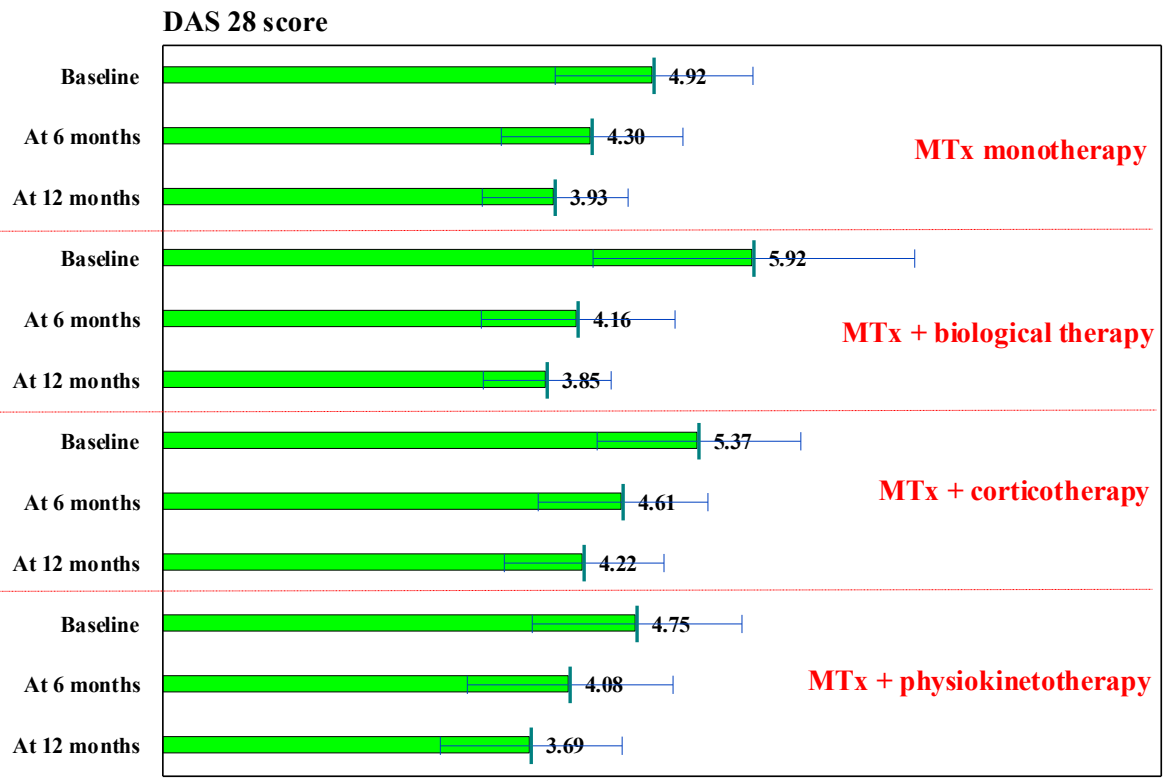

Figure 3.

Evolution of DAS28 score with different treatment strategies

\section{SDAI score}

In addition to the parameters used in the DAS28 score, the SDAI score adds the physician's overall assessment, a patient global assessment of disease activity and CRP value [4]. The following painful/ swollen joints are considered: shoulder, elbows, wrists, MCP 1 - 5, PIP 1 - 5, knees. Values above 40 indicate intense activity, 20 - 40 moderate activity, under $20 \mathrm{RA}$ is minimal active and a value below 5 is equivalent to remission. It is useful in assessing the response to treatment [11]. 
FARMACIA, 2019, Vol. 67, 3

The effect on SDAI score in the 6-month evaluation was moderate in MTx monotherapy and MTx + physiokinetotherapy $(\mathrm{ES}=0.76$, respectively $\mathrm{ES}=0.79)$, and more significant in MTx + biological therapy and MTx + corticotherapy $(\mathrm{ES}=1.13$, respectively $\mathrm{ES}=0.97)$.
The effect on SDAI score after 12-month study was significant in all treatment strategies $(\mathrm{ES}=1.00$ in MTx monotherapy, ES $=1.28$ in MTx +biological therapy, $\mathrm{ES}=1.25$ corticotherapy, respectively $\mathrm{ES}=$ 1.18 in MTx + physiokinetotherapy) (Figure 4).

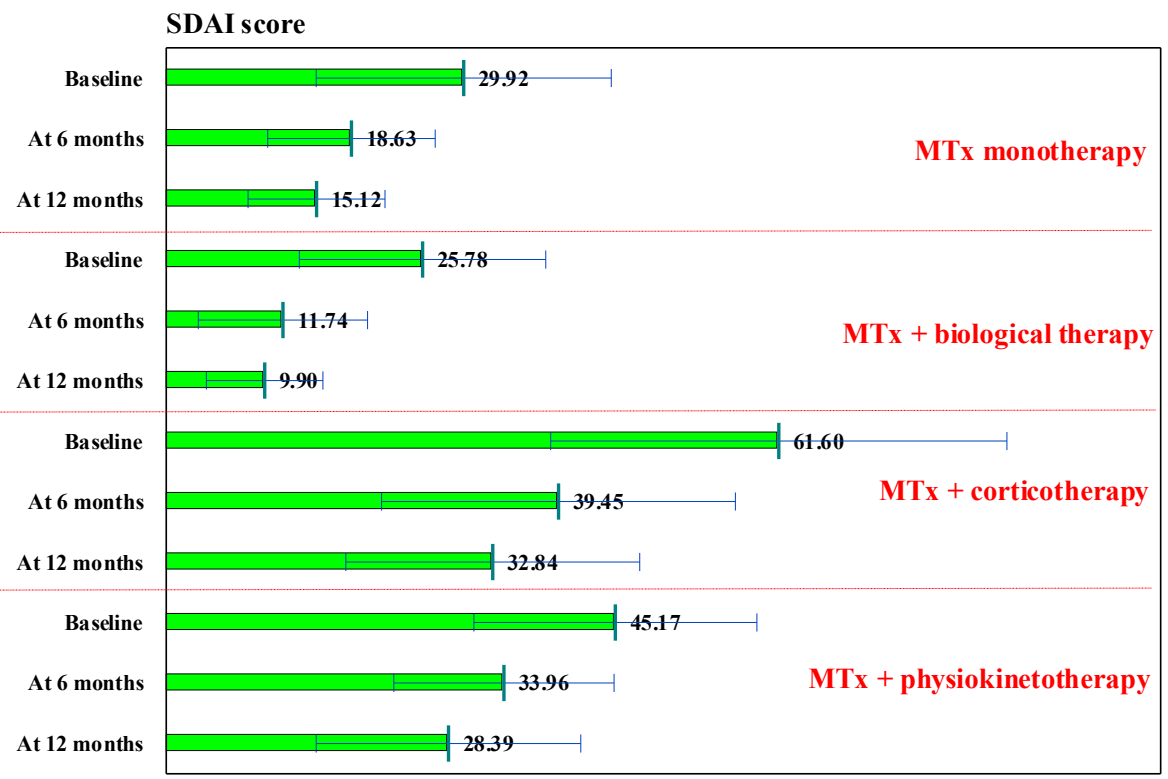

Figure 4.

Evolution of SDAI score with different treatment strategies

$V A S$

The effect on VAS score after 6-month was moderate in MTx monotherapy, MTx + corticotherapy and $\mathrm{MTx}+$ physiokinetotherapy $(\mathrm{ES}=0.57, \mathrm{ES}=0.74$, respectively $\mathrm{ES}=0.64)$, and significant in $\mathrm{MTx}+$ biological therapy $(\mathrm{ES}=1.10)$.
The effect on VAS score in the 12-month evaluation was significant in all treatment strategies $(\mathrm{ES}=0.85$ in MTx monotherapy, $\mathrm{ES}=1.61$ in MTx + biological therapy, $\mathrm{ES}=0.95$ in $\mathrm{MTx}+$ corticotherapy, respectively $\mathrm{ES}=0.91$ in MTx + physiokinetotherapy) (Figure 5).

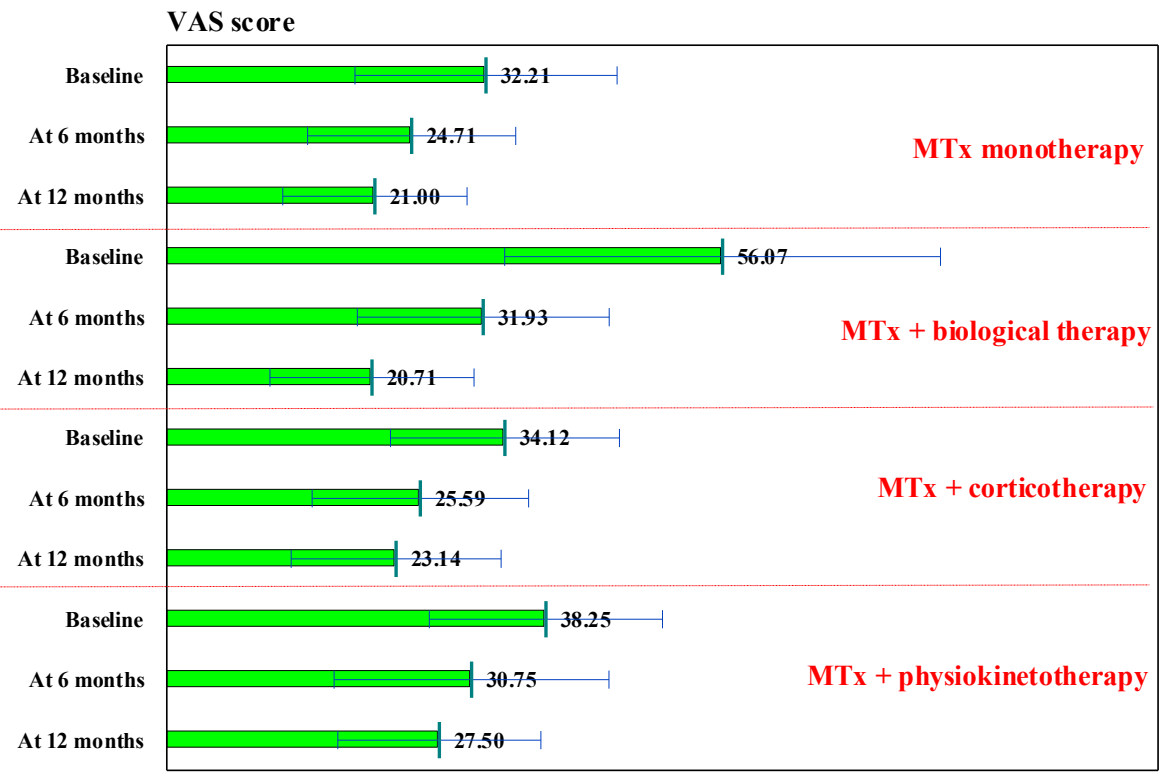

Figure 5.

Evolution of VAS score with different treatment strategies 
From this study we observed that the prevalence of developing RA is greater in female individuals, regardless the stage of the disease, with age between 56 - 62 years.

Taking into focus the serologic tests, we noticed an improvement of overall inflammatory factors such as ESR, CRP, and RF.

The most important effect in obtaining the remission state on DAS28 score was detected in MTx + biological therapy group in 6 months evaluation $(\mathrm{ES}=1.09)$. All treatment strategies recorded a significant improvement in the 12 months evaluation.

The SDAI evaluation also showed that in MTx monotherapy the remission was not recorded at 6 and 12 months. In MTx + biological therapy the remission was recorded in one patient $(7.14 \%)$ at 6 and 12 months. In MTx + corticotherapy the remission was not recorded at 6 months and recorded one patient $(5.88 \%)$ at 12 months. In MTx + physiokinetotherapy the remission was recorded in one patient $(5.00 \%)$ at 6 months and not recorded at 12 months.

The effect of 6-month on SDAI score was significant in MTx + biological therapy and MTx + corticotherapy $(\mathrm{ES}=1.13$, respectively $\mathrm{ES}=0.97)$ and the effect of 12-month on SDAI score was significant in all treatment strategies (ES $=1.00$ in MTx monotherapy, $\mathrm{ES}=1.28$ in $\mathrm{MTx}+$ biological therapy, $\mathrm{ES}=$ 1.25 MTx + corticotherapy, respectively $\mathrm{ES}=1.18$ in MTx + physiokinetotherapy).

The effect on VAS score after 6-month check was significant in MTx + biological therapy $(\mathrm{ES}=1.10)$ and significant in all treatment strategies $(\mathrm{ES}=0.85$ in MTx monotherapy, ES = 1.61 in MTx + biological therapy, $\mathrm{ES}=0.95$ in MTx + corticotherapy, respectively $\mathrm{ES}=0.91$ in MTx + physiokinetotherapy) after 12 months evaluation.

\section{Conclusions}

The biological therapy has a significant efficiency in the treatment and management of RA associated with older generations of DMRD's. The outcome of this study revealed the overall efficiency of biological therapy and MTx in all evaluations, with the most patients with a remission, with significant improvements in DAS28 score $(\mathrm{ES}=1.29)$, SDAI score $(\mathrm{ES}=1.28)$, VAS $(E S=0.95)$. Serologic analyses also revealed an improvement of overall inflammatory factors such as ESR, CRP, and RF in the MTx + biological therapy group after a 12 months study.

All these results are in direct correlation with the positive overall therapy response in patients with RA.

Physiokinetotherapy is very important in the management of RA symptoms and slowing down the progression of the disease. In the present study, the MTx + Physiokinetotherapy group obtained better overall results comparative with the MTx monotherapy group. Further studies are to be made in order to evaluate the benefits of associating it to the Biological Therapy + MTx.

\section{References}

1. Aletaha D, Neogi T, Silman AJ, Funovits J, Felson DT, Bingham CO 3rd, Birnbaum NS, Burmester GR, Bykerk VP, Cohen MD, Combe B, Costenbader KH, Dougados M, Emery P, Ferraccioli G, Hazes JM, Hobbs K, Huizinga TW, Kavanaugh A, Kay J, Kvien TK, Laing T, Mease P, Ménard HA, Moreland LW, Naden RL, Pincus T, Smolen JS, StanislawskaBiernat E, Symmons D, Tak PP, Upchurch KS, Vencovsky J, Wolfe F, Hawker G, 2010 rheumatoid arthritis classification criteria: an American College of Rheumatology/European League Against Rheumatism collaborative initiative. Ann Rheum Dis., 2010; 69(9): 1580-1588.

2. Allaart CF, Goekoop-Ruiterman YP, de Vries-Bouwstra JK, Breedveld FC, Dijkmans BA, FARR study group, Aiming at low disease activity in rheumatoid arthritis with initia combination therapy or initial monotherapy strategies. Clin Exp Rheumatol., 2006; 24(6 Suppl 43): S-77-82.

3. Alves C, Early detection of patients at risk for rheumatoid arthritis- a challenge for primary and secondary care. Erasmus University Rotterdam, 2015, https://repub.eur.nl.

4. American College of Rhumatology, 2013, www.rheumatology.org.

5. Boissier M, Semerano L, Challal S, Saidenberg Kermanac'h N, Falgarone G, Rheumatoid arthritis: from autoimmunity to synovitis and joint destruction. J Autoimmun., 2012; 39(3): 222-228.

6. Brzustewicz E, Bryl E, The role of cytokines in the pathogenesis of rheumatoid arthritis-Practical and potential application of cytokines as biomarkers and targets of personalized therapy. Cytokine, 2015; 76(2): 527-536.

7. Chandrashekara S, Current studies of biomarkers for the early diagnosis of rheumatoid arthritis. Current Biomarker Findings, 2014:4 107-119.

8. Codreanu C, Popescu CC, Mogosan CD, Enache L, Manda G, Berghea F, Groseanu L, Predeteanu D, Targeting interleukin 17 in the treatment of rheumatoid arthritis. Farmacia, 2018; 66(3): 390-398.

9. Davis JM, Matteson EL, My treatment approach to rheumatoid arthritis. Mayo Clin Proc., 2012; 87(7): 659-673.

10. Hawker GA, Mian S, Kendzerska T, French M, Measures of adult pain: Visual Analog Scale for Pain (VAS Pain), Numeric Rating Scale for Pain (NRS Pain), McGill Pain Questionnaire (MPQ), Short-Form McGill Pain Questionnaire (SF-MPQ), Chronic Pain Grade Scale (CPGS), Short Form-36 Bodily Pain Scale (SF-36 BPS), and Measure of Intermittent and Constant Osteoarthritis Pain (ICOAP). Arthritis Care Res (Hoboken), 2011; 63 (Suppl 11): S240-252.

11. Humphreys JH, Warner A, Chipping J, Marshall T, Lunt M, Symmons DP, Verstappen SM, Mortality trends in patients with early rheumatoid arthritis over 20 years: results from the Norfolk Arthritis 
Register. Arthritis Care Res (Hoboken), 2014; 66(9): 1296-1301.

12. Klippel JH, Primer on the rheumatic diseases $13^{\text {th }}$ ed. New York, NY, Springer; Arthritis Foundation, 2008.

13. Krabben A, Huizinga TW, van der Helm-van Mil $\mathrm{AH}$, Undifferentiated arthritis characteristics and outcomes when applying the 2010 and 1987 criteria for rheumatoid arthritis. Ann Rheum Dis., 2012; 71(2): 238-241.

14. Mateen S, Zafar A, Moin S, Khan AQ, Zubair S, Understanding the role of cytokines in the pathogenesis of rheumatoid arthritis. Clin Chim Acta, 2016; 455: 161-171.

15. McInnes IB, Buckley CD, Isaacs JD, Cytokines in rheumatoid arthritis - shaping the immunological landscape. Nat Rev Rheumatol., 2016; 12(1): 63-68.

16. National Health Insurance House, Eligibility criteria for inclusion in Alpha tumor necrosis factor (TNF $\alpha$ ) blocker therapy and some second-choice remission therapies and choice of treatment regimen in patients with rheumatoid arthritis. www.cnas.ro.

17. Nogueira E, Gomes A, Preto A, Cavaco-Paulo A, Update on therapeutic approaches for rheumatoid arthritis. Curr Med Chem., 2016; 23(21): 2190-21203.

18. Radu CP, Management of rheumatoid arthritis patients in Romania. Management in Health, 2011; 15(2).

19. Schiotis RE, Goșa D, Bocșan C, Suciu S, Buzoianu $\mathrm{AD}$, Particularities of treatment with conventional synthetic disease-modifying antirheumatic drugs (DMARDs) in a group of patients with rheumatoid arthritis. Farmacia, 2017; 65(3): 479-484.

20. Wallach JB, Interpretation of diagnostic tests $7^{\text {th }}$ edition. Lippincott Williams \& Wilkins Publishers, 2000.

21. Wolfe F, Bellamy N, Prognosis in the rheumatic diseases. Springer Science \& Business Media, 2012. 